Pilar Arnau i Segarra Universitat de les Illes Balears parnausegarra@gmail.com

\title{
La invisibilidad de la literatura ecuatoguineana
}

\section{Resumen:}

Guinea Ecuatorial fue una colonia española hasta 1968. El español sigue siendo la lengua oficial, y la lengua de expresión literaria. La literatura de Guinea Ecuatorial es la gran desconocida de todas las literaturas hispanas. Son muchos los factores que generan su invisibilidad. El objetivo de este artículo es una breve aproximación a la joven literatura de Guinea Ecuatorial y analizar los factores que originan su invisiblidad.

Palabras clave: Guinea Ecuatorial; literaturas hispanoafricanas; invisibilidad literaria

\section{Abstract:}

\section{The Invisibility of the Equatorial Guinea's Literature}

Equatorial Guinea was a Spanish colony until 1968. Spanish is the official language, and the language of literary expression. The literature of Equatorial Guinea is the great unknown of all Hispanic literatures. Many different factors generate their invisibility. The objective of this article is to scope the young literature of Equatorial Guinea and to analyze the factors that originate its invisibility.

Keywords: Equatorial Guinea; Hispanic-African Literatures; Literary invisibility 


\section{Contextualización introductoria}

Seguramente que si hoy en día hiciéramos una encuesta a pie de calle en cualquier ciudad española muy pocas personas sabrían contestar a la siguiente pregunta:

“¿Tuvo España colonias en el África subsahariana?"

Y todavía un número menor de los posibles entrevistados respondería correctamente a la pregunta:

"¿Conoce las fechas de la colonización española de Guinea Ecuatorial?".

Ciertamente, las respuestas, si las hubiera, podrían sorprender por el gran desconocimiento de la sociedad española sobre la existencia de las colonias españolas en África, y sobre el mero hecho de que Guinea Ecuatorial haya sido - la única — colonia española al sur del desierto del Sahara. ${ }^{1}$

El territorio aproximado que hoy denominamos Guinea Ecuatorial pasó del dominio portugués al español en 1778, tras el tratado de San Ildefonso (1777) y de El Pardo (1778). Mediante dichos tratados, Portugal cedía a España diversas islas y territorios de la costa del golfo de Guinea y, con ello, los derechos de trata de esclavos.

Bajo el dominio español, Guinea tuvo distintos estatus, es decir, el entonces denominado Río Muni se convirtió en protectorado en 1886, y en colonia en 1900. Más tarde, en 1926, se reunificaron diversos territorios (Colonia de Río Muni, isla de Fernando Poo, Colonia de Elobey, Annobón, Corisco y diversas islas del golfo), convirtiéndose

1 Cabe reconocer que desde finales de 2015 ha aumentado el conocimiento social de Guinea Ecuatorial en España con el gran éxito de taquilla de la película "Palmeras en la nieve". Dirigida por Fernando Fernández Molina, se trata de la versión cinematográfica de la novela homónima de Luz Gabás, publicada tan sólo tres años antes, en 2012, y que ya ha sido traducida a nueve idiomas. La película, con un exotismo exagerado y unos paisajes (Colombia y Tenerife) que no se corresponden a los lugares que describe, narra las hazañas de un grupo de colonos del pirineo aragonés que emigraron a Guinea Ecuatorial, concretamente a la isla de Fernando Poo (hoy llamada Bioko), para dedicarse a la explotación del cultivo del cacao. "Numerosos intelectuales y escritores guineanos se apresuraron, sin embargo, en salirle al paso de la crítica" (Sampedro, 2015). 
todos ellos en la Guinea Española. En 1958 su estatus cambió al de región española y en 1963, tras un referéndum, al de región autónoma española. En 1968, bajo la presión de gran parte de la población, sin olvidar la que ejerció las Naciones Unidas, dicho territorio proclamó la independencia y el país adoptó el nombre de República de Guinea Ecuatorial.

Visto lo visto, la respuesta a la segunda pregunta que nos planteábamos, es decir, las fechas de inicio y final de la colonización española de Guinea serían pues, con ciertos intermedios, de 1778 a 1968, cerca de 200 años, ¡casi nada para pasar desapercibidos!

\section{Sobre las lenguas de Guinea Ecuatorial}

E1 desconocimiento actual de la relación entre España y Guinea Ecuatorial no se remite solamente al ámbito histórico o al político. Pocos españoles saben que en este país, a pesar de las circunstancias históricas desfavorables, el castellano sigue siendo la lengua oficial, junto con el francés ${ }^{2}$. En 1968, tras la independencia, "Francisco Macías prohibió el uso de esta «lengua imperialista» — muchos murieron por hablarla o escribirla - [y] su sobrino y sucesor, Teodoro Obiang, adscribió el país a la Francofonía, y lo integró entre los Países de Expresión Portuguesa, «cooficializando» así el francés y el portugués, sin razón histórica o cultural que lo avale" (Ndongo-Bidyogo, 2015: 12).

Las lenguas autóctonas más habladas son el fang, que es la lengua mayoritaria, el bubi, el ndmé y así hasta cinco lenguas distintas. Sin llegar a ser consideradas completamente ágrafas, ninguna de ellas tiene un soporte escrito habitual, ni una ortografía regularizada. La situación socio-lingüística del castellano en Guinea Ecuatorial con respecto a las otras lenguas reúne una serie de características que la convierten en un fenómeno lingüístico bastante singular.

2 A pesar de la cooficialidad del español con el francés, la sociedad ecuatoguineana tiene cada día un mayor interés en el aprendizaje del inglés debido a motivos económicos y comerciales, sobre todo a partir de los descubrimientos de grandes yacimientos de petróleo y de gas en el país, que han aumentado considerablemente las relaciones internacionales. 
Gloria Nistal Rosique asegura que dicha situación socio-lingüística es única:

En efecto, a diferencia del resto de los países de habla hispana, el español hablado por la mayoría de la población no es una lengua materna, sino una segunda lengua. Todos los guineanos — prosigue la hispanista — pertenecen a una de las cinco etnias que hablan sus propias lenguas nativas. (Nistal Rosique: 74)

Así, pues, existe una gran diversidad de lenguas habladas, pero, en general, la población de Guinea Ecuatorial aprende el castellano en la escuela, pues tanto la enseñanza primaria como la secundaria se realizan en esta lengua. El castellano es una lengua con un elevado nivel de prestigio social, es la lengua de la educación, y la de los medios de comunicación escritos y audiovisuales, y la de la política. Hoy por hoy, y mientras el Sahara Occidental no sea un estado independiente reconocido por las Naciones Unidas, Guinea Ecuatorial es el único país del continente africano que tiene el castellano como lengua oficial. Esta oficialidad ha ido cambiando a través del tiempo, desde la independencia de 1968, tal como hemos explicado anteriormente . Actualmente, podemos leer en el artículo $4^{\circ}$ de La Ley Fundamental de Guinea Ecuatorial, promulgada el 16 de febrero de 2012 que

1. Las lenguas oficiales de la República de Guinea Ecuatorial son el Español, el

Francés y las que la Ley determine. Se reconocen las lenguas autóctonas como

integrantes de la cultura nacional.

En 2013, un año después de la promulgación de la cooficialidad del español con el francés, el gobierno ecuatoguineano inició la creación de la Academia Ecuatoguineana de la Lengua Española, que fue aprobada por el Presidente Obiang en enero de 2014. Desde marzo de 2016 dicha Academia forma parte de la Asociación de Academias de la Lengua Española, al igual que las otras veintidós asociaciones nacionales de la lengua. 
Teniendo en cuenta el estatus de oficialidad del castellano en Guinea Ecuatorial y su relación con las otras lenguas existentes, nos resultará más fácil entender las raíces de la literatura escrita en español en este país africano tan alejado físicamente de la Península Ibérica, y rodeado por países cuyas lenguas oficiales son el francés o el inglés, $\mathrm{o}$ incluso ambas.

\section{Circunstancias geopolíticas y lingüísticas}

Los escritores ecuatoguineanos y los especialistas en su literatura se quejan muy a menudo de la falta de divulgación y conocimiento de la literatura de Guinea Ecuatorial en España. Al contrario del progresivo reconocimiento de la literatura negro africana de expresión francesa o inglesa, la literatura ecuatoguineana de expresión castellana no goza de la mínima divulgación necesaria para llegar al lector; es más, podríamos afirmar que se la sigue ignorando desde la época colonial hasta nuestros días. M'bare N'gom Fayé ${ }^{3}$ publicó en 2003 un incisivo artículo sobre la ausencia de dicha literatura en el debate crítico y teórico español. Ponía como ejemplo el resultado de su propia experiencia. N'gom había analizado unas cuarenta obras generales sobre literatura hispana (especialmente antologías e historias de la literatura), publicadas entre 1977 y 1993, tanto en España como en América Latina o en los Estados Unidos de América. Solamente en dos de ellas se encontró alguna referencia a obras literarias ecuatoguineanas (N'gom Fayé, 2003).

En efecto, mientras que las literaturas negroafricanas de expresión francesa o inglesa llegan, desde ya hace decenios, y muy dosificadas, a las librerías de Europa, la literatura de expresión castellana se encuentra con un gran número de inconvenientes, muchos de los cuales son de naturaleza geopolítica.

M'bare N'gom Fayé es catedrático de la Morgan State University y especialista en la literatura de afrodescendientes. Sin duda es el estudioso más prolífico de la literatura ecuatoguineana de expresión castellana. Véase la lista bibliográfica al final de este trabajo. 
El nacimiento de la literatura africana escrita en lenguas europeas está vinculado a su relación y dependencia intelectual con la colonia. Los primeros escritos en inglés de autoría negro-africana aparecieron en la segunda mitad del siglo XIX, y los franceses a principios del XX, cuando París empezó a convertirse en una poderosa fuente de atracción cultural para artistas, estudiantes y escritores africanos. "Madrid, en cambio, nunca llegó a asumir ni a desempeñar ese papel para los guineanos u otros africanos radicados en España". (N'gom Fayé, 2010: 25). Por otra parte, ningún escritor o intelectual guineano participó en los grandes congresos internacionales de escritores y artistas negros, como el de París (1956), el de Roma (1959) u otros que se celebraron en los años 60 en la Unión Soviética. Otra circunstancia diferenciadora entre las literaturas de expresión inglesa o francesa y la castellana remite a la propia lucha anti-colonial: en la mayor parte de las colonias africanas la literatura asumió un papel de defensa nacionalista y anticolonial. En otras palabras: muchos de los grandes dirigentes nacionalistas africanos que lucharon por la independencia de su país fueron también escritores que lograron crear una literatura nacionalista, anticolonialista, lo cual no ocurrió en la Guinea Española donde la literatura apenas presentó resquicios nacionalistas hasta los años sesenta. En el territorio colonial español africano no se produjeron grandes textos literarios anticoloniales, antes al contrario, muchos de los textos escritos durante la colonia comulgaban abiertamente con el discurso colonial español. Por otra parte, las primeras creaciones literarias en castellano de autoría guineana aparecieron a mediados de la década de los cuarenta del siglo XX, es decir, unos treinta años más tarde que la literatura producida en las zonas anglófonas o francófonas (N’gom Fayé, 2010: 24-26).

\section{Reivindicación canónica}

A pesar de todas estas circunstancias desfavorables, los escritores ecuatoguineanos reivindican desde hace decenios su pertenencia al canon literario español. Se escudan, explícitamente, en la lengua como denominador común, y defienden la aportación lingüística enriquecedora 
que representa la literatura hispanoafricana en el contexto de la literatura escrita en castellano, ya que consiste en la "expresión de diferentes realidades culturales desde variaciones literarias que aportan una evidente pluralidad a la lengua española" (Miampika, 2010: 14).

La lengua es por tanto el motivo sobre el que se fundamenta dicha literatura, el rasgo característico que la define. Su pertenencia al canon español viene determinada pues por la lengua en que está escrita. En otras palabras, se considera que la aportación más valiosa de las escrituras hispanoafricanas a la literatura es el enriquecimiento de la lengua española.

Hay que tener en cuenta que, precisamente a causa de su filiación lingüística, Guinea Ecuatorial es considerada por algunos hispanistas como el epicentro de las literaturas hispanoafricanas. No podemos olvidar que en Camerún y sobre todo en Marruecos existen voces literarias que se manifiestan en castellano, como Robert Marie Johlio o Inongo Vi-Makomé (Alvarado, 2010). También cabe recordar aquí los muy diversos autores marroquíes, estudiados entre otros por Christián Ricci $(2010,2014,2015)$, o los escritores saharauis. ${ }^{4}$ A pesar de ello, el caso de Guinea Ecuatorial sigue siendo notable y singular. Sin una escritura depurada en las lenguas autóctonas, el castellano no es solamente una de las lenguas oficiales del país, sino también la lengua de expresión literaria de la gran mayoría de sus escritores literarios.

El proceso de legitimación de la literatura guineoecuatoriana no se afianzó hasta mediados de los años 80 , cuando el escritor y político Donato Ndongo-Bidyogo publicó un volumen que se convirtió rápidamente en obra de referencia obligada: Antología de la literatura guineana (1984). Dicha antología abrió las puertas a un primer intento

4 Desde comienzos del siglo XXI se han multiplicado las ediciones de antologías de escritores saharauis que escriben en castellano. La denominada "Generación de la amistad de la poesía saharaui", de la que forman parte escritores como Liman Boicha, Saleh Abdalahi, Ebnu, Chejdan Mahmud, Mohamed Ali Ali Salem, Zahra Hasnaui, Ali Salem Iselmu o Bahia Awat. La última antología hasta ahora ha aparecido en diciembre de 2016: VerSahara 2016 (Las Palmas de Gran Canaria: Cuadernos de La Gueldera), en la que se editan poemas de dichos autores y de poetas canarios. 
de canonización de esta literatura. Según Miampika este es "un libro dinámico y movilizador que asentó los cimientos y diseñó la posibilidad de una literatura nacional escrita, de una literatura guineoecuatoriana" (Miampika, 2010: 15).

Bajo el título Literatura de Guinea Ecuatorial, Ndongo-Bidyogo publicó en el año 2000 una versión ampliada de esta antología en la que ya colaboró M'bare N'gom y en la que se incluyeron nuevas voces literarias aparecidas en los años 90 del siglo XX.

No es nuestro objetivo, y sería realmente imposible, hacer un repaso exhaustivo de la literatura ecuatoguineana. Sin embargo nos gustaría ahora ofrecer unas breves pinceladas que podrían marcar algunos itinerarios de lectura. ${ }^{5}$ La primera novela de la que tenemos conocimiento es Cuando los combes luchaban, que lleva el subtítulo aclaratorio (novela de costumbres de la Guinea Ecuatorial), de Leoncio Evita Enoy. Dicha novela fue publicada en 1953, todavía en pleno contexto colonial español. A ella le sucedieron un par de obras que ensalzaban el colonialismo español y cuyos autores luchaban por usar el castellano con un mínimo de torpezas lingüísticas.

En los años 60, a las puertas de la independencia, los escritores guineanos se decantaron por el cultivo de la poesía. Una poesía que comenzaba a mostrar algunos tintes nacionalistas, y que a veces presentaba títulos tan significativos como El león de África (1964), de Juan Chema Mijero.

Tras la independencia de 1968, se estableció el durísimo régimen del dictador Francisco Macías, que generó la huida y el exilio de miles de guineanos. La poesía fue el principal género del discurso de resistencia cultural en el exilio. De entre los distintos poetas exiliados destacamos a Juan Balboa Boneke (Rébola 1938 - Valencia 2014). Balboa, que había estudiado en la Universidad de Granada, tuvo que exiliarse con su familia durante la dictadura de Macías. En 1969 se estableció con su familia en Mallorca, donde publicó diversos libros

5 Buena parte de la información que sigue procede de M'Bare N'gom Fayé (2010). 
de poemas y ensayos ${ }^{6}$. Volvió a Guinea con los signos de apertura de Obiang a mediados de los ochenta, quien le encargó diversas carteras ministeriales, entre ellas la de Cultura, pero en 1994, tras la deriva autoritaria del Presidente, decidió exiliarse de nuevo, esta vez a la ciudad de Valencia, donde vivió hasta su muerte. Balboa tematizó el exilio como una experiencia solitaria, alienante, dolorosa y muy traumática. El escritor exiliado no sólo publicó poesía, sino también diversos libros de ensayos donde mezclaba los propios recuerdos con la historia de su país. La incomunicación y sobre todo la crisis de identidad del exiliado son los dos centros de gravedad de su obra ensayística. Así, según afirma N'gom Fayé (2010: 30) en el libro de Balboa ¿Dónde estás Guinea?, publicado en 1978 en Mallorca, el autor se pregunta amargamente:

¿Quién soy yo? Se me ha arrancado de lo que era mi realidad, mi existencia, mi cultura [...] Ni soy de aquí, ni soy de allá. Y cuando me descubro a mí mismo resulta que para mis hermanos (mi pueblo) soy un extraño. Sigo sintiéndome extraño en esta sociedad porque no acabo de sentirme comprendido, porque no acabo de comprender. (Balboa, 1978: 11)

La obra de Juan Balboa es uno de los testimonios más desgarradores del exilio ecuatoguineano, el del escritor que se siente desterritorializado e impotente.

En ese mismo año de 1978 aparece la primera pluma femenina de la literatura africana en castellano. Se trata de la entonces joven autora Raquel Ilonbé, cuyo verdadero nombre es Raquel del Pozo Epita, hija de padre español y madre guineana. Su poemario Ceiba es precisamente el único texto de ese período que no encaja en el discurso del exilio y la resistencia cultural predominante. La poeta nació en Guinea pero se trasladó a la Península Ibérica a la edad de dos años, donde vivió primero en Burgos y más tarde en Madrid, donde falleció en 1992.

La poesía guineana de los años ochenta recurrirá a motivos tan terribles como la mutilación de los cuerpos, la destrucción sistemática

6 Entre los hijos que tuvo Balboa en Mallorca se encuentra la famosa cantante Concha Buika (Palma, 1972). 
o los fusilamientos masivos, temas relacionados con la realidad social y política de la dictadura que se sufría en el país. Evidentemente, estas obras fueron publicadas en el exilio, la mayoría en pequeñas editoriales españolas.

Tras las reflexiones identitarias de Juan Balboa Boneke, aparecieron otros ensayos que reflexionaban sobre el doloroso exilio ecuatoguineano, como El problema humano (1985), del filósofo Eugenio Nkogo Ondo. Se trata de un conjunto de veintitrés ensayos escritos durante diez años donde recoge la experiencia traumática y dramática del exilio y de la diáspora guineana.

Recordemos que en 1979 acabó el régimen tiránico de Francisco Macías, y se inició un intento de democratización del país, que será abortado solamente unos años más tarde con la deriva del régimen de Teodoro Obiang hacia posiciones autoritarias. Sin embargo, en los primeros años se vivió una cierta primavera cultural y literaria. Se publicaron algunos libros importantes, como la novela de Balboa $E l$ reencuentro. El retorno del exiliado (1985), y la Antología de la literatura guineana (1984), de Donato Ndongo-Bidyogo, a la que nos hemos referido anteriormente.

En 1987, Donato Ndongo-Bidyogo (Niefang, 1950) publica su primera novela: Las tinieblas de tu memoria negra, un texto clave para entender la literatura africana en castellano. Las tinieblas es la primera entrega de una trilogía cuya segunda parte, Los poderes de la tempestad, se publicó en 1997, y El metro, en 2007. Ndongo-Bidyogo es sin duda uno de los autores guineanos más prolíficos, y uno de los pocos cuya obra ha sido objeto de estudio individual en diversas ocasiones ${ }^{7}$. Escritor y periodista, ha sido director adjunto del Centro Cultural Hispano-Guineano de Malabo, delegado de la Agencia EFE en África Central, y director del Centro de Estudios Africanos en la Universidad de Murcia. Entre 2005 y 2008, fue profesor visitante en la Universidad de Missouri-Columbia (Estados Unidos). Además de las cuatro obras que ya hemos citado, ha publicado Historia y tragedia de Guinea

7 Véase el listado bibliográfico al final del artículo de Natalia Álvarez Mén$\operatorname{dez}(2015:$ 42-43). 
Ecuatorial (1977) o España en Guinea (1998), entre otras. Algunos de sus libros han sido traducidos al inglés y al francés. Ndongo-Bidyogo merecería un estudio a parte. Su faceta intelectual muestra la voluntad de reconstruir mediante sus textos la "verdad" de la historia colonial y poscolonial en su país (Álvarez Méndez, 2015: 25). Sin olvidar que su faceta periodística y su actividad política (Otabela, Onomo Abena, 2008), están ambas orientadas hacia la lucha contra el régimen autoritario y a favor de la democratización del país.

Con el cambio de siglo han surgido nuevas voces literarias, muchas de ellas vinculadas a nuevos exilios, y en todo caso publicadas casi siempre en España. Predomina ahora la narrativa. Autores como el médico José Eneme Oyono con Más allá de deber (2005), una novela que transcurre en la época colonial; Inocencio Engon con Nostalgia de un emigrante (2004), una novela que explora la realidad de la emigración - también es autor de algunos poemarios; o Remei Sipi Mayo, con sus Cuentos africanos de 2005; o el poeta y narrador residente en Estados Unidos Juan Davies, autor de una decena de títulos entre narrativa y poesía. Y así, hasta una treintena de autores que han aparecido o se han consolidado ya en nuestro siglo XXI (Tomás Cámara, 2010: 307-323).

En general, la literatura ecuatoguineana focaliza especialmente la pugna entre el individuo y el estado postcolonial, es decir, la lucha del sujeto por la emancipación. Pero esta emancipación no se percibe desde la perspectiva lingüística, pues los escritores se sitúan en una

relación compleja y dolorosa con la lengua española, una lengua de expresión más adoptada que heredada, unas particulares condiciones de escritura, una interacción problemática entre escritor y público [...] estas voces hispanoafricanas ponen en tela de juicio múltiples aristas de la identidad lingüística a raíz de la procedencia de los escritores. (Miampika, 2010: 16)

Los autores de la literatura guineanoecuatoriana han experimentado un proceso de apropiación creativa del español, pero ¿están obligados a asumir y expresar la alteridad cultural y la variedad lingüística de la cual proceden? En dicho contexto, cabe preguntarse hasta qué punto dicha literatura hispanoafricana debería incorporar el habla popular, las sutilezas, los localismos o los giros idiomáticos del castellano africano, 
en un contexto plurilingüe como lo es el de Guinea Ecuatorial. Es aquí donde aparecen las tensiones de subversión, de transgresión o de reapropiación en una relación problemática con la lengua de escritura (Miampika, 2010: 17). En otras palabras, el castellano no es la lengua materna de los escritores ecuatoguineanos, sino la lengua que aprenden en la escuela - la mayoría de los niños que acuden a los colegios hablan únicamente fang, bubi, ndowé o annobonés en sus hogares y con su familia, y no el español (Nistal Rosique: 74) - , con lo cual se advierten posibles tensiones lingüísticas entre las lenguas maternas nativas y el español en el proceso de creación literaria.

\section{La recepción}

No cabe duda de que las literaturas hispanoafricanas tienen una recepción muy problemática. Su ausencia total y absoluta en los libros escolares y en los manuales de historia de la literatura, así como en las antologías de literaturas hispánicas, y el todavía escaso interés despertado en los centros académicos españoles así lo confirman. Cabe citar, sin embargo, los grupos de investigación dirigidos por Josefina Bueno de la Universitat d'Alacant y los de Inmaculada Díaz Narbona de la Universidad de Cádiz, sin olvidar la Biblioteca Africana virtual del Instituto Cervantes, dirigida por la misma profesora J. Bueno ${ }^{8}, \mathrm{y}$ algunos departamentos de Hispánicas en universidades extranjeras, especialmente norteamericanas, como el de Hofstra University, dirigido por Benita Sampedro Vizcaya, auténtico centro neurálgico de los estudios coloniales hispánicos, donde se celebran regularmente congresos y otros acontecimientos vinculados con la literatura africana de expresión española.

Por otra parte, la gran mayoría de las obras literarias de autoría ecuatoguineana están publicadas en pequeñas editoriales, con tiradas muy bajas que no superan, en muchos casos, los 500 ejemplares, y en ediciones muy modestas, que a menudo (sobre todo en el caso de

8 Véase: Bibioteca Africana, [on-line] http://www.cervantesvirtual.com/ portales/biblioteca_africana/. 
antologías) no llegan a las 100 páginas. Siempre se trata de editoriales ubicadas fuera de Guinea Ecuatorial, la mayoría en España, y en algunos casos están dirigidas, e incluso pertenecen, a los propios escritores. Este es el caso de la Editorial Mey, de Barcelona, cuya editora es la escritora y activista feminista ecuatoguineana Remei Sipi. La Editorial Mey, fundada en 1995, ha publicado hasta la fecha quince volúmenes, tres de los cuales son de la propia Sipi, que también colabora en otros dos volúmenes de su editorial. La autoedición es muy habitual en la literatura ecuatoguineana. Con todos estos datos, es fácil imaginar que la recepción periodística sea poco importante. Se concentra en revistas digitales sobre el mundo africano y en webs o páginas de facebook sobre afrodescendientes en España. ${ }^{9}$ No obstante encontramos alguna excepción, como el artículo de Benita Sampedro en el suplemento cultural del periódico madrileño $A B C$ : "Las nuevas voces de Guinea Ecuatorial", del 12 de diciembre de 2016. Tan excepcional es dicho artículo que ha sido reproducido seis veces en tan sólo unas semanas en la página de facebook más importante sobre cultura africana en España. ${ }^{10}$

Aunque la recepción mediática y el interés académico no sean muy elevados, cabe destacar que un puñado de africanistas, la mayoría jóvenes profesores universitarios, algunos de origen africano residentes en Europa o EEUU, publican estudios sobre aspectos concretos de la literatura ecuatoguineana. Una parte importante de esta bibliografía crítica la encontramos en la colección Biblioteca Hispanoafricana de la Editorial Verbum de Madrid, y dirigida por Landry-Wilfrid Miampika, profesor en la Universidad de Alcalá de Henares. Hasta ahora se han publicado doce volúmenes, entre los que destacaríamos dos compilaciones de artículos: De Guinea Ecuatorial a las literaturas hispanoafricanas (2010), editado por el propio Miampika, y Literaturas

9 https://www.facebook.com/Espa $\% \mathrm{C} 3 \% \mathrm{~B} 1$ oles-Afrodescendientes-y-Di\%C3\%A1 spora-Africana-en-Espa\%C3\%B1a-491292597603820/?fref=ts (3.11.2016)

10 Remito a la nota 10. 
hispanoafricanas: realidades y contextos $(2015) \cdot{ }^{11}$ La mayoría son estudios reunidos sobre dicha literatura, antologías poéticas, ensayos generales sobre la obra de alguno de los autores más destacados. En estos volúmenes, así como en las antologías y muchas publicaciones y entrevistas de Donato Ndongo-Bidyogo se percibe una clara voluntad de canonización y una reivindicación implícita del reconocimiento de la literatura ecuatoguineana.

\section{Algunas posibles causas de la invisibilidad}

Una literatura joven, sin tradición propia, que se publica en reducidas tiradas en pequeñas editoriales extranjeras, una literatura que no forma parte del canon oficial y que todavía no ha sido "descubierta" por los representantes de la crítica literaria oficial es difícil que obtenga el reconocimiento que reclama. Asimismo, otros elementos juegan un rol importante en su invisibilidad.

Hasta ahora nos hemos referido sobre todo a los factores y al contexto europeo español. Pero sería muy necesario acercarnos al contexto cultural de Guinea Ecuatorial. Gustau Nerín, editor y antropólogo catalán especialista en dicha literatura, achaca la invisibilidad de la literatura ecuatoguineana a diversos factores, unos se centran en la recepción y otros se ubican en la situación político-cultural del mismo país de procedencia. Nerín (2010: 299-303) advierte del hecho de que esta literatura es, en gran parte, completamente desconocida en la propia Guinea Ecuatorial. Recordemos que muchos de los autores están exiliados y por tanto sus obras están proscritas en su país nativo. Pero además, hay que tener en cuenta algunos datos muy significativos que condicionan el número de lectores y la divulgación y el (des)conocimiento de esta literatura. La situación de los medios de comunicación en el país es catastrófica: a la censura política en los medios que se podría esperar en un país de régimen dictatorial, hay que sumarle la ausencia de multiplicadores culturales. Según afirmaba

11 Pueden consultarse los datos bibliográficos completos en la lista de bibliografía final de este artículo. 
Donato Ndongo-Bidyogo en una entrevista, en 2006 aún "no había prensa escrita, ni cines, ni bibliotecas" en Guinea Ecuatorial e incluso se había prohibido la lectura de prensa extranjera (Otabela, Onomo Abena, 2008: 226-227). Nerín (2010: 300) advierte por su parte que en Guinea Ecuatorial no existe ni una sola librería y que las pocas bibliotecas adscritas a la universidad apenas tienen fondos bibliográficos, ya que sus espacios se utilizan sobre todo para estudiar los apuntes dictados por los profesores. Nerín, que fue profesor en la Universidad de Malabo, afirma con vehemencia que "La mayoría de los estudiantes universitarios no han leído jamás un sólo libro. Los profesores de literatura se limitan a dictar biografías de autores y listados de sus obras, y ellos mismos no leen nada de nada." (Nerín, 2010: 300). Los hábitos de lectura son por tanto poco significativos y en este contexto el número de lectores ha de ser mínimo. Para contrarrestar dicha situación, en 2012 el propio Nerín impulsó, junto con Mariano Ekomo y J. Fernando Siale, la creación de la primera librería en Guinea Ecuatorial „La Librería de Bata”, ubicada en el Centro Cultural de España, y que pertenece a la asociación ecuatoguineana "Página de Luz". Dicho proyecto en Bata pudo ser puesto en marcha gracias a la Agencia Española de Cooperación Internacional para el Desarrollo (AECID). Poco después se ha abierto una segunda librería asociada, también en un Centro Cultural Español, esta vez en la capital, Malabo.

Por otra parte, la escasez de editoriales en Guinea Ecuatorial obliga a muchos autores a autoeditarse, lo cual depende en gran medida de las subvenciones que puedan obtener de entidades extranjeras, principalmente de fondos de la Cooperación Española. Esta dependencia de las subvenciones convierte a la literatura guineana en un ente frágil, ya que no depende de sus lectores, sino de diferentes agentes externos. Y si tenemos en cuenta que la mayor parte de las subvenciones proceden de un país que está sufriendo una fuerte crisis económica como es España, la fragilidad se agrava.

Otro factor que recrudece la invisibilidad de esta literatura procede de sus propios defensores: los especialistas, a menudo autores africanos pero también jóvenes universitarios occidentales, autores de los trabajos más recientes, tienden a practicar una cierta discriminación 
positiva y muy a menudo cometen el error de asumir el rol de entusiastas aplaudidores en lugar del de críticos literarios.

la literatura guineana se ha convertido en la única literatura del mundo que no tiene escritores malos y en la que ningún autor ha producido una obra floja. Esta tendencia a sobrevalorar toda la producción literaria guineana ha tenido efectos tremendamente perniciosos, al nivelar a todos los textos: si todos son buenos, todos son malos. Las obras de mayor calidad han quedado sepultadas bajo el alud de textos menos brillantes, y esto tiende a rebajar el nivel de la literatura guineana a los ojos de la crítica. (Nerín, 2010: 301)

Al ensalzamiento que achaca Nerín a ciertos estudiosos habría que sumarle el hecho de que muchos de los lectores interesados en esta literatura se acercan a estos textos por motivos emocionales (vínculos familiares o amistosos con personas ecuatoguineanas; viajeros y turistas) o simplemente por su exótica procedencia. En otras palabras: por lo general estas obras sólo son leídas por personas interesadas en Guinea Ecuatorial, y no por personas que gozan con la lectura literaria.

\section{A modo de conclusión}

La literatura de Guinea Ecuatorial de expresión española está sentenciada, por ahora, a la invisibilidad. Ello se debe a múltiples factores muy diversos, tanto de carácter histórico como socioculturales o políticos. Surgió más tarde que las demás literaturas negroafricanas a causa del retraso en el despliegue educativo español y sufrió un gran parón durante la dictadura de Macías debido a la sangrienta represión política y al descenso del nivel educativo. La situación actual no es mucho mejor, sin un mercado editorial, con escasas bibliotecas y un control absoluto de la información por parte del gobierno de Obiang, se impide la creación cultural en libertad.

Sin embargo, empiezan a percibirse algunos signos positivos, como son el elevado número de autores que están publicando en los últimos años, la mayoría exiliados en Europa o América del Norte, lo cual nos lleva a pensar que podría elevarse también el nivel de dicha literatura 
y con ello el número de lectores $\mathrm{y}$, consecuentemente, su necesaria visibilidad en el mundo de las literaturas hispanas.

(Mallorca, enero de 1917)

\section{Bibliografía}

ALVARADO, M.J. (2010), "La literatura africana en español, un nuevo camino para el encuentro", en: Miampika L.-W., Arroyo, P. (eds.), De Guinea Ecuatorial a las literaturas hispanoafricanas, Verbum, Madrid, pp. 303-307.

DDAA (2016), VerSahara 2016, Cuadernos de La Gueldera, Las Palmas de Gran Canaria.

MANRIQUE SABOGAL, W. (2016), "La literatura invisible de Guinea Ecuatorial. Escritores de la antigua colonia reclaman mayor atención de su Gobierno y de España", El País - Cultura, 23/10/ 2016, [online] http:// cultura.elpais.com/cultura/2016/10/23/actualidad/1477222999_250129. $\mathrm{html}$ ?rel=mas\#comentarios, 1.11.2016.

N'GOM FAYÉ, M'B. (1996), Diálogos con Guinea. Panorama de la literatura guineoecuatoriana de expresión castellana a través de sus protagonistas, Labrys 54, Madrid.

N'GOM FAYÉ, M'B. (2003), "Literatura africana de expresión española", en: Cuadernos Centros de Estudios Africanos 3, [online] http://www.asodegue.org/ddiciembre0803.htm, 1.11.2016.

N'GOM, M'B. (ed.) (2004), La recuperación de la memoria : creación cultural e identidad nacional en la literatura hispano-negroafricana, Servicio de Publicaciones de la Universidad de Alcalá de Henares, Alcalá de Henares.

N'GOM FAYÉ, M’B. (2010), “La literatura africana de expresión castellana: de una «literatura posible» a una literatura real. Etapas de un proceso de creación cultural", en: Miampika L.-W., Arroyo, P. (eds.), De Guinea Ecuatorial a las literaturas hispanoafricanas, Verbum, Madrid, pp. 23-40. 
NERÍN, G. (2010), "La literatura guineana desde el punto de vista editorial", en: Miampika L.-W., Arroyo, P. (eds.), De Guinea Ecuatorial a las literaturas hispanoafricanas, Verbum, Madrid, pp. 209-302.

NISTAL ROSIQUE, G. / PIÉ JAHN, G. (2008), La situación actual del español en África, Editorial Sial, Madrid.

CASTRO, M.L. de, CALLE, M.L. de la (2007), La colonización española en Guinea Ecuatorial (1858-1900), CEIBA Ediciones, Vic.

NDONGO-BIDYOGO, D. (1984), Antología de la literatura guineana, Editorial Nacional, Madrid.

NDONGO-BIDYOGO, D. (2015), "De la inexistencia conceptual a la visibilización de las otras literaturas hispánicas”, en: Díaz Narbona, I. (coord.), Literaturas hispanoafricanas: realidades y contextos, Verbum, Madrid, pp. 11-17.

OTABELA, J.-D., ONOMO ABENA, S. (2008), Entre estética y compromiso. La obra de Donato Ndongo-Bidyogo, Madrid: Servicio de Publicaciones de la UNED.

RICCI, Ch. (2010), Literatura periférica en castellano y catalán: el caso marroquí, Ediciones del Orto, Madrid.

RICCI, Ch. (2014), ¡Hay moros en la costa! Literatura marroqui fronteriza en castellano y catalán, Iberoamericana/Vervuert, Madrid/Frankfurt.

RICCI, Ch. (2015), "Marruecos: poesía y narrativa social e independentista escrita en castellano", en: Díaz Narbona, I., Literaturas hispanoafricanas: realidades y contextos, Verbum, Madrid, pp. 324-354.

SAMPEDRO, B. (2016), "Las nuevas voces de Guinea Ecuatorial", en: $A B C-C u l t u r a l, 12 / 12 / 2016$, [online] http://www.abc.es/cultura/cultural/abci-nuevas-voces-guinea-ecuatorial-201612110112_noticia.html, 20.01.2017.

TOMÁS CÁMARA, D. (2010), "Literaturas hispanoafricanas: bibliografía selecta", en: Miampika L-W., Arroyo, P. (eds), De Guinea Ecuatorial a las literaturas hispanoafricanas, Verbum, Madrid, pp. 307-323.

Bibliografía virtual:

N'GOM FAYÉ, M'B., "La literatura africana en español”, [on-line] http:// www.cervantesvirtual.com/portales/biblioteca_africana/introduccion_corpus/, 24.12.2016. 
NISTAL ROSIQUE, G., “El caso del español en Guinea Ecuatorial”, [on-line] http://cvc.cervantes.es/lengua/anuario/anuario_06-07/pdf/paises_08.pdf, 25.12.2016.

La Ley Fundamental de Guinea Ecuatorial, [on-line] http://www.droit-afrique.com/upload/doc/guinee-equatoriale/GE-Constitution-2012-ESP.pdf, 21.12.2016.

Biblioteca Africana de la Biblioteca Virtual Cervantes, [on-line] http://www. cervantesvirtual.com/portales/biblioteca_africana/, 22.12.2016. 